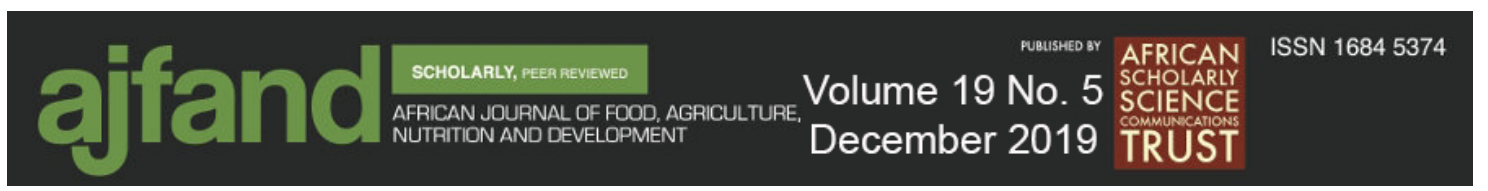

University of Illinois - SIL Farm.Doc Series

Afr. J. Food Agric. Nutr. Dev. 2019; 19(5): 15136-15139 DOI: 10.18697/ajfand.88.SILFarmDoc06

\title{
SOYBEAN VARIETIES IN SUB-SAHARAN AFRICA
}

Michelle Santos ${ }^{1}$

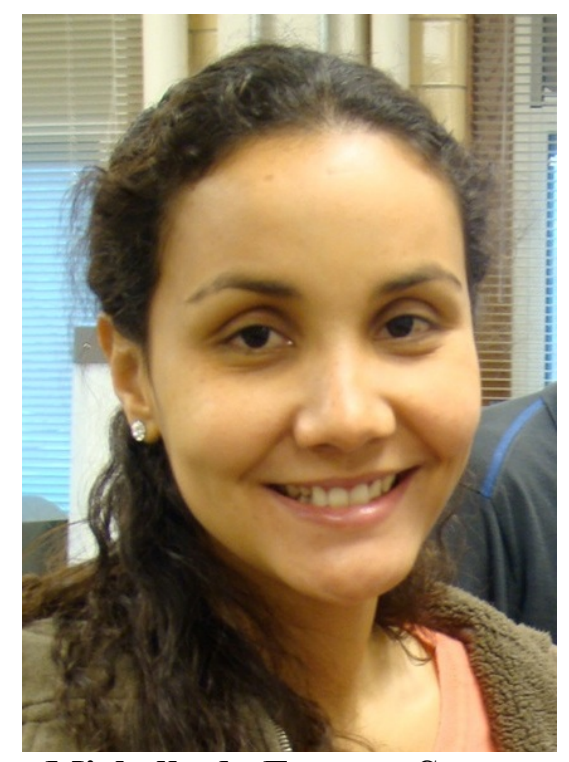

Michelle da Fonseca Santos

About the Author

${ }^{1}$ Dr. Michelle Santos, a former soybean breeder with Monsanto, Brazil, is the program manager for the Pan- African Soybean Variety Trials at the Soybean Innovation Lab at the University of Illinois at Urbana-Champaign

Email: mdfsanto@,illinois.edu 
Soybean is a growing global commodity crop with strong demand due to its use as an edible oil and as a key ingredient in animal feeds, such as for poultry. However, soybean is a new crop in Africa and there are few high- yielding variety options available especially to smallholder farmers. As such, soybean yields experienced by African smallholder farmers are significantly lower than yields experience in other soybeanproducing areas of the world.

To provide smallholder farmers access to high-yielding soybean varieties that can increase and diversify their sources of on-farm income, the Soybean Innovation Lab (SIL), with partners at the Syngenta Foundation for Sustainable Agriculture (SFSA), the International Institute of Tropical Agriculture (IITA), and the African Agricultural Technology Foundation (AATF), created the Pan-African Soybean Variety Trials (PATs) program. The goal of the PATs is to fast-track the identification and commercialization of new, high-yielding soybean varieties that grow well in African environments and have enhanced overall seed quality, which should ultimately result in profitable soybean production for smallholder farmers in Africa.

The PATs began with a four-location trial in Malawi during 2016. Today, trials are underway in 13 additional countries: Benin, Cameroon, Ethiopia, Ghana, Kenya, Mali, Mozambique, Nigeria, Rwanda, Sudan, Uganda, Zambia, and Zimbabwe (Figure 1). The trials span over 70 locations and evaluate between 20 and 40 soybean lines supplied by international seed producers from eight African countries, the U.S., Brazil, Colombia, and Australia.

The trial provides yield results from single locations and across multiple locations, so lines with consistent high yield can be identified. In addition to yield, other traits are also evaluated in the PATs that are important to variety selection such as: number of days to maturity, lodging, shattering, seed weight, and protein and oil concentration. Maturity date is used to determine adaptation to diverse environments (Liu et al., 2017) such as day length and temperature conditions. Selection for low lodging and shattering is desired to minimize harvest losses. Seed size (measured as 100-seed weight) is determined for each line and growers often prefer large seed varieties, as they are easier to thresh and clean compared to small seed varieties. Protein and oil are seed components of great economical value for food, animal feed, and industrial use.

In Malawi, soybean is well adapted for production in all agro-ecological zones (Kananji et al., 2013). However, soybean yields are still low, as smallholders obtain 29.4-36.7 bushels per hectare on average (Malawi Soybean Outlook, 2016). There are eight soybean varieties currently registered for commercial production in Malawi, but the most popular variety is eight years old.

With financial support from Palladium International, the PATs tested more than 70 soybean lines during three seasons in Malawi, and a fourth season is underway. In the 2017-18 growing season, 36 lines were tested while the 2018 winter season 40 lines were tested under irrigation. During both seasons, high yielding experimental lines were identified and some yielded greater than the commercial variety, Tikolore, 
although none significantly out yielded this variety. In the summer, the highest yield for a soybean line across testing locations was 88.2 bushels per hectare and in the winter it was 95.5 bushels per hectare. During the summer season in Mpale, which received irrigation to remove drought stress, the highest yield line produced was 150.7 bushels per hectare. Mpale was also the location with the highest mean across all cultivars for kilograms of oil per hectare $(466.3 \mathrm{~kg} / \mathrm{ha})$ and kilograms of protein per hectare $(933.7 \mathrm{~kg} / \mathrm{ha})$. These results show the importance of combining highyielding genetics with the use of best practices for soybean production and management.

To prepare for registration and release of selected high yielding varieties, lines selected in the 201718 summer season were retested in the PATs during the 2018-19 summer season in eight locations (Figure 2) and in on- farm tests in seven sites across Malawi, where each site had three host farmers. The next step is to submit a release proposal with data from the stations and on-farm trials across seasons to the Agricultural Technology Clearing Committee(ATCC).

Other countries like Cameroon, Uganda, and Rwanda planted the first PATs in 2018 and identified soybean lines with potential to become commercial releases. The tests were grown in three or four environments in each country and the average yield across locations for the highest yielding lines ranged from 44.1 to 51.5 bushels per hectare, greater than the commercial varieties used as controls in the tests. The three countries are repeating the tests in 2019 to evaluate performance consistency across years. PATs are currently growing in Benin, Ethiopia, Ghana, Kenya, Mali, Mozambique, Nigeria, Zambia, and Zimbabwe and the results from these trials will enable the selection of high performing soybean lines in these countries.

Identification of new soybean genetics performing better than the local varieties, with adaptation to the agro- zones and presenting high seed quality is driving the success of the PATs. The registration and release of new soybean varieties across countries should positively affect the soybean value chain in Africa.

\section{References}

Kananji, G.A.D., Yohane, E., Siyeni, D., Kachulu, L., Mtambo, L., Chisama, B.F., Malaidza, H., Tchuwa, F., \& Mulekano, O. (2013). A guide to soybean production in Malawi. DOI: 10.13140/2.1.4982.2723.

Liu, X., Wu, J., Ren, H., Qi, Y., Li, C., Cao, J., Zhang, X., Zhang, Z., Cai, Z., \& Gai, J. (2017). Genetic variation of world soybean maturity date and geographic distribution of maturity groups. Breeding Science, 67(3), 221-232. Retrieved from https://www.ncbi.nlm.nih.gov/pmc/articles/PMC5515309.

Malawi Soybean Outlook. (2016, September). Retrieved from http://www.aiccafrica.org/index.php?option=com_content\&view=article\&id=63\&Ite $\mathrm{mid}=140 \&$ jsmallfib $=1 \&$ dir $=$ JSROOT/Outlooks. 


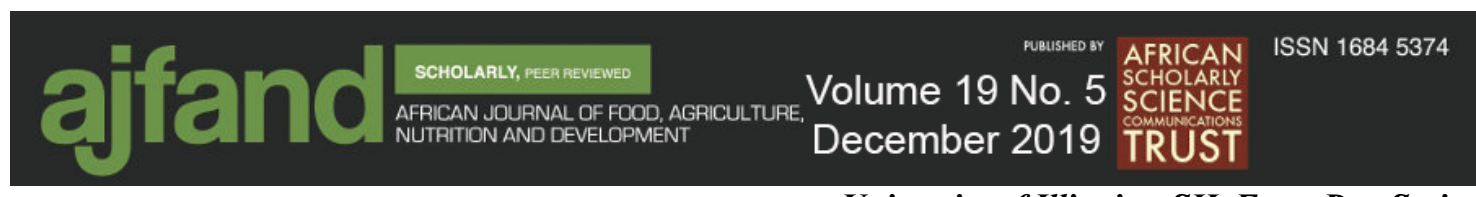

University of Illinois - SIL Farm.Doc Series

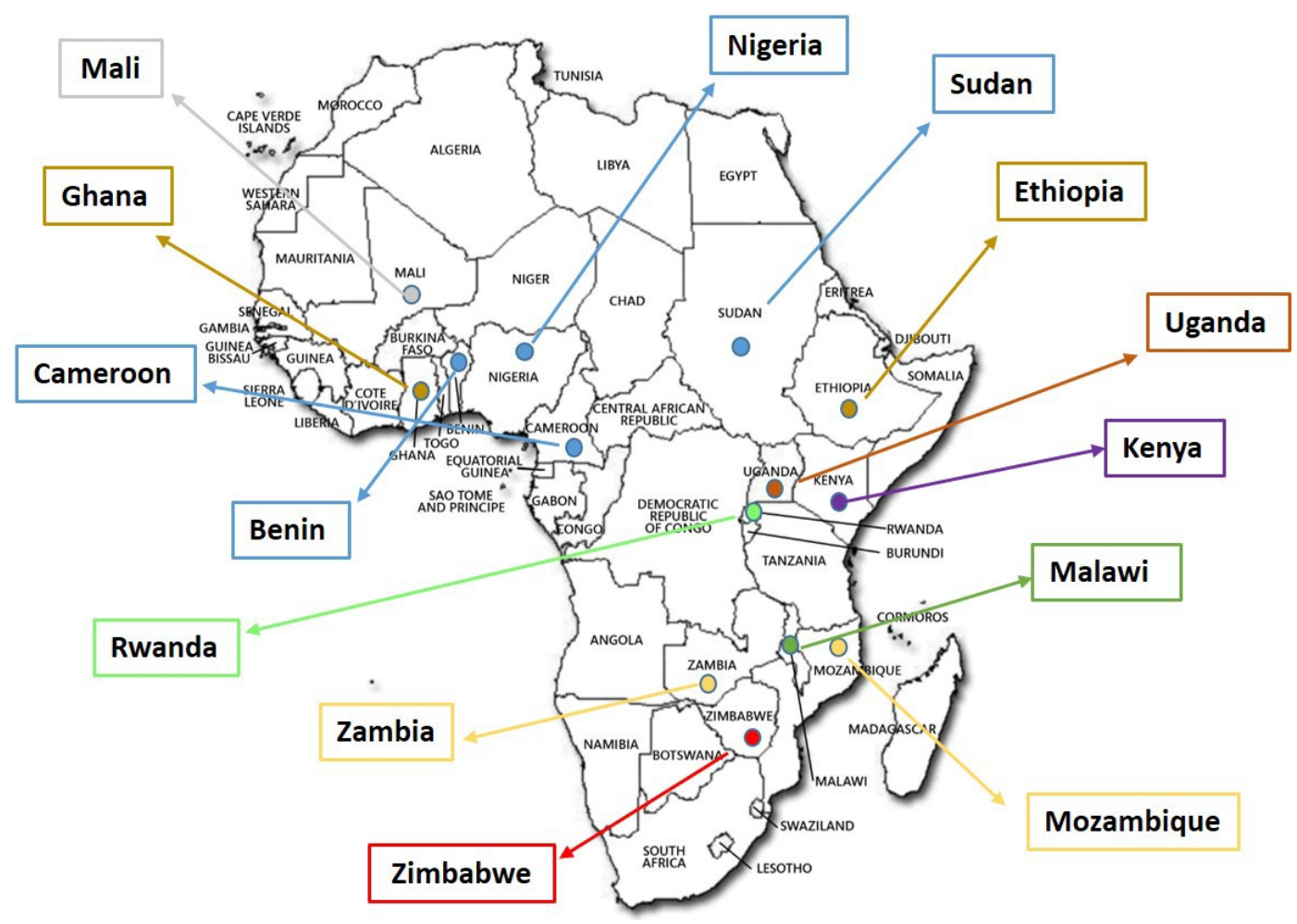

Figure 1: African countries where the Pan-African Soybean Variety Trials are implemented

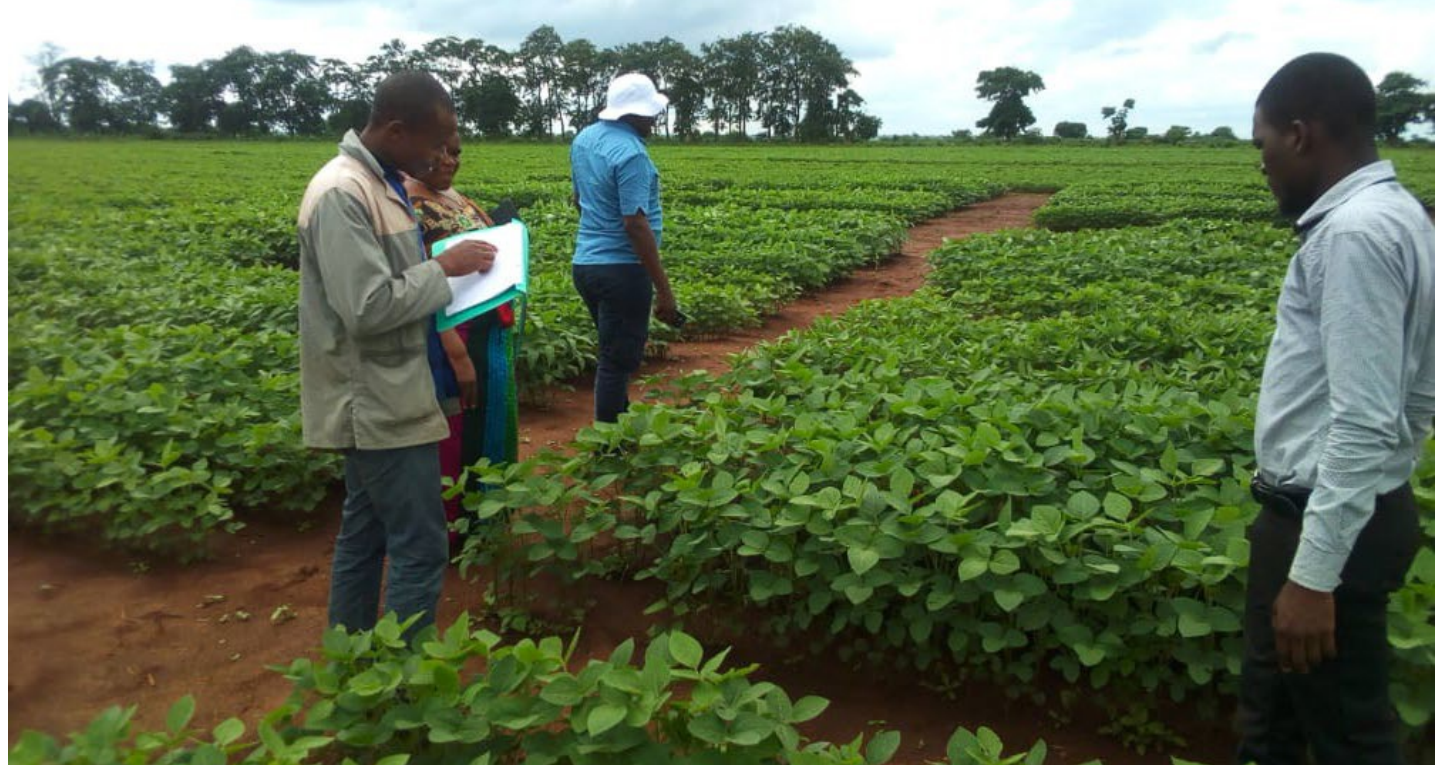

Figure 2: Soybean trials at Chitedze, Malawi - 2018/19 season. Photo credit: Department of Agricultural Research Services(DARS) 